\title{
Thermal sensation: a mathematical model based on neurophysiology.
}

Citation for published version (APA):

Kingma, B., Schellen, L., Frijns, A., \& van Marken Lichtenbelt, W. D. (2012). Thermal sensation: a mathematical model based on neurophysiology. Indoor Air, 22(3), 253-262. https://doi.org/10.1111/j.16000668.2011.00758.x

Document status and date:

Published: 01/06/2012

DOI:

10.1111/j.1600-0668.2011.00758.x

Document Version:

Publisher's PDF, also known as Version of record

Document license:

Taverne

Please check the document version of this publication:

- A submitted manuscript is the version of the article upon submission and before peer-review. There can be important differences between the submitted version and the official published version of record.

People interested in the research are advised to contact the author for the final version of the publication, or visit the DOI to the publisher's website.

- The final author version and the galley proof are versions of the publication after peer review.

- The final published version features the final layout of the paper including the volume, issue and page numbers.

Link to publication

\footnotetext{
General rights rights.

- You may freely distribute the URL identifying the publication in the public portal. please follow below link for the End User Agreement:

www.umlib.nl/taverne-license

Take down policy

If you believe that this document breaches copyright please contact us at:

repository@maastrichtuniversity.nl

providing details and we will investigate your claim.
}

Copyright and moral rights for the publications made accessible in the public portal are retained by the authors and/or other copyright owners and it is a condition of accessing publications that users recognise and abide by the legal requirements associated with these

- Users may download and print one copy of any publication from the public portal for the purpose of private study or research.

- You may not further distribute the material or use it for any profit-making activity or commercial gain

If the publication is distributed under the terms of Article $25 \mathrm{fa}$ of the Dutch Copyright Act, indicated by the "Taverne" license above, 


\section{Thermal sensation: a mathematical model based on neurophysiology}

\begin{abstract}
Thermal sensation has a large influence on thermal comfort, which is an important parameter for building performance. Understanding of thermal sensation may benefit from incorporating the physiology of thermal reception. The main issue is that humans do not sense temperature directly; the information is coded into neural discharge rates. This manuscript describes the development of a mathematical model of thermal sensation based on the neurophysiology of thermal reception. Experimental data from two independent studies were used to develop and validate the model. In both studies, skin and core temperature were measured. Thermal sensation votes were asked on the sevenpoint ASHRAE thermal sensation scale. For the development dataset, young adult males $(N=12,0.04 \mathrm{Clo})$ were exposed to transient conditions; $T_{\text {air }} 30-20$ $35-30^{\circ} \mathrm{C}$. For validation, young adult males $(N=8,1.0 \mathrm{Clo})$ were exposed to transient conditions; $T_{\text {air }}: 17-25-17^{\circ} \mathrm{C}$. The neurophysiological model significantly predicted thermal sensation for the development dataset $\left(r^{2}=0.89\right.$, $P<0.001)$. Only information from warm-sensitive skin and core thermoreceptors was required. Validation revealed that the model predicted thermal sensation within acceptable range (root mean squared residual $=0.38$ ). The neurophysiological model captured the dynamics of thermal sensation. Therefore, the neurophysiological model of thermal sensation can be of great value in the design of high-performance buildings.
\end{abstract}

\section{B. R. M. Kingma ${ }^{1}$, L. Schellen ${ }^{2}$, A. J. H. Frijns ${ }^{3}$, W. D. van Marken Lichtenbelt ${ }^{1}$}

${ }^{1}$ Department of Human Biology, NUTRIM School for Nutrition, Toxicology and Metabolism of Maastricht University Medical Centert, Maastricht, The

Netherlands, ${ }^{2}$ Department of Architecture, Building and Planning, Unit Building Physics and Systems, Eindhoven University of Technology, Eindhoven, The Netherlands,

${ }^{3}$ Department of Mechanical Engineering, Eindhoven

University of Technology, Eindhoven, The Netherlands

Key words: Thermal sensation; Thermal reception; Neurophysiology; Neural integration; Mathematical model; Building design.

\section{B. Kingma}

Department of Human Biology

Maastricht University

Universiteitssingel 50, P0 Box 616, NL-6200 MD

Maastricht, The Netherlands

Tel.: +31 (0)433884260

Fax: +31 (0)43 3670976

e-mail: b.kingma@maastrichtuniversity.nl

Received for review 26 April 2011. Accepted for

publication 15 November 2011.

\section{Practical Implications}

The presented method, based on neurophysiology, can be highly beneficial for predicting thermal sensation under complex environments with respect to transient environments.

\section{Introduction}

Thermal comfort, determined by the influence of the indoor environmental parameters on thermal sensation, is regarded as an important performance indicator of building performance. Therefore, accurate mathematical models of thermal sensation are extremely useful in design of new high-performance buildings. Recently, de Dear (2011) reintroduced the concept of 'thermal alliesthesia', which deals with the neurophysiological mechanisms responsible for thermal sensation. According to de Dear, with the concept of alliesthesia it should be possible to explain in the future: 'why occupants of today's so called sustainable buildings can enjoy positive indoor environmental quality in indoor climates that would have failed the criteria established under yesterday's standards of thermal comfort'.

In this study we aim to expand the synthesis between neurophysiology and mathematical modeling to make a better prediction of the thermal sensation. One of the key principles in the neurophysiology of thermal reception is that humans do not sense temperature directly. Temperature information is coded into the firing rate of temperature-sensitive neurons (thermoreceptors). These neurons are found all over the body. Two types of thermoreceptors can be distinguished: 'cold' or 'warm' sensitive (see Figure 1). Skin contains both types of thermoreceptors, whereas deeper laying tissues (e.g., intestines, spinal cord, and hypothalamus) 


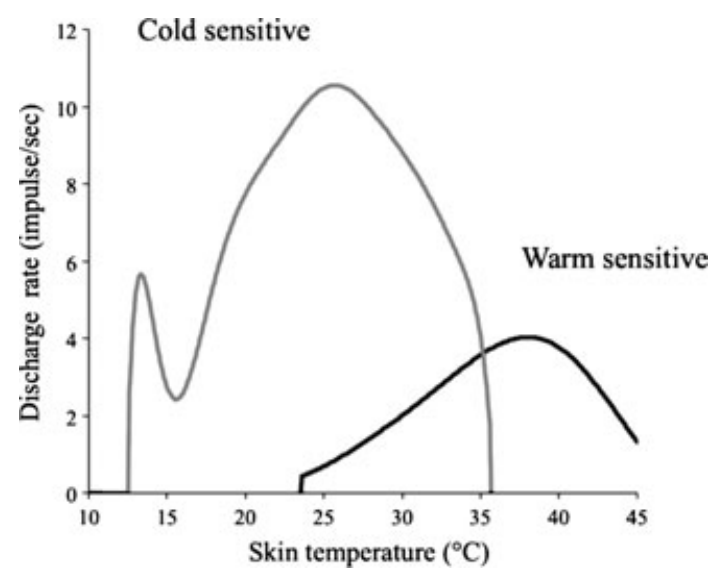

Fig. 1 Averaged steady state neuron discharge rate vs. skin temperature for cold sensitive (gray line) and warm sensitive (black line) neurons of cat tongue (after (Mekjavic and Morrison, 1985; Zotterman, 1953))

contain mostly warm-sensitive thermoreceptors (Boulant, 2006).

The main hypothesis is that through simulation of the neurophysiological pathways the dynamics of thermal sensation can be captured. Therefore, we developed a new model for thermal sensation based on the neurophysiology of thermal reception and integration through neural pathways.

\section{Context}

Both thermal comfort and energy use play an important role in the performance of a building. About one-third of the primary energy used in developed countries is consumed by heating, ventilating, and air conditioning in residential, commercial, and public buildings (IEA, 2007). This reveals the high importance of reducing the energy use in buildings. However, satisfaction of the occupants with their thermal environment mainly determines the success of the application of low-energy Heating Ventilation and Air Conditioning (HVAC) systems. Much effort has been taken to design optimal energy HVAC systems; this resulted in among others, low temperature heating systems, high temperature cooling systems, different ventilation principles, etc. However, the Annex 37 (Juusela, 2003) study revealed that an optimal energy use does not always results in an increased comfort level. Non-uniform thermal conditions, which may occur owing to application of lowenergy systems, can be responsible for discomfort [e.g., a low temperature floor heating system in combination with natural ventilation (Boerstra et al., 2000)]. Contrary, Arens et al. (2006) concluded that through asymmetrical and transient thermal environments, higher levels of thermal comfort could be achieved in comparison with steady-state uniform environments. Regarding transient environments, de Dear and Brager
(2001) concluded that satisfaction with the thermal environment does not mean that this environment has to be controlled at a constant indoor air temperature (de Dear and Brager, 2001). A study by Schellen et al. (2010) confirmed this statement. Furthermore, compared to a constant temperature, allowing the temperature to drift could be a means to reduce energy use.

To adequately design optimal environmental conditions in the future, both in an energy-friendly and comfortable way, more knowledge on the interaction between the system, indoor climate, and the human body is indispensable.

\section{Thermal sensation}

Thermal sensation and satisfaction with the thermal environment is a complex phenomenon, and therefore complicated to predict in the design phase. Owing to the large differences between persons, both psychological and physiological, it is difficult to satisfy everyone in the same room. Many researchers have studied the parameters that affect thermal sensation with the objective of developing a model to predict thermal sensation. The most used and referred model is the predicted mean vote (PMV) model of Fanger (1970). This model is included in current building standards to predict thermal sensation, and therefore often used to assess the thermal comfort in the design phase. This model intended to be a method that could be used by HVAC engineers to determine the optimum environmental conditions (combination of air temperature, mean radiant temperature, relative humidity, mean air velocity, activity level, and clothing) to satisfy the largest possible percentage of a given group of occupants. It was assumed that a person is most comfortable in a thermal neutral condition, which is defined as the condition wherein a person does not prefer either a colder or warmer environment.

Although this method is frequently used and implemented in building regulations, many researchers showed the limitations of the model, e.g., for differences between subpopulations (males/females, young/ older people, etc), thermal neutrality, expected discomfort, and driving mechanisms (dependent parameters), for thermal comfort (de Dear and Brager, 2001; Humphreys and Hancock, 2007, Nakano et al., 2002; Parsons, 2002; Schellen et al., 2010; Van Hoof, 2008).

According to de Dear (2011), the PMV theory from Fanger led to the thermal comfort mantra 'cool, dry, still indoor air', which was achieved by static isothermal indoor climates. As described above, a growing interest is on dynamic non-uniform environments as they can provide an energy-saving potential, more comfortable environment, and probably healthier environment (de Dear, 2011; Johnson et al., 2011). The above-mentioned studies indicate there is a need for new sensation models that cope with dynamic, 
transient environments and individual effects and requirements.

de Dear et al. (1993) showed with a mathematical simulation that the discharge rate of skin thermoreceptors correlated to the change in thermal sensation during sudden temperature transitions (de Dear et al., 1993). Hence simulating the actual physiology of humans (i.e., neuron discharge rate instead of using skin temperatures) can be highly beneficial when designing buildings while optimizing energy costs and thermal comfort.

\section{Neurophysiology of thermal reception}

Most knowledge of thermoreceptor responses comes from experiments on isolated nerves of anesthetized animals (e.g., cats, rabbits, and primates); nevertheless, the fundamental properties of thermoreception also have been confirmed in man (Hensel, 1981). Still, the exact neuron discharge rate vs. temperature may differ substantially between species or between tissues. However, the general characteristics of thermoreception are assumed to be sufficient to serve the purpose of this study.

Zotterman et al. (1953) reported the averaged nonlinear characteristic of thermoreceptor firing rates from steady-state temperature experiments on cat tongue. The maximum steady-state discharge rate for coldsensitive receptors lies around $25^{\circ} \mathrm{C}(11 \mathrm{impulses} / \mathrm{s})$ and for warm-sensitive receptors the maximum firing rate lies around $38^{\circ} \mathrm{C}$ (4 impulses/s) (Dodt and Zotterman, 1952, Zotterman, 1953). Contrary, other researchers showed that in cat nose the maximum steady-state discharge rate for cold-sensitive receptors was at $27^{\circ} \mathrm{C}$ (9 impulses/s) and for warm-sensitive neurons the maximum was at $46^{\circ} \mathrm{C}$ (36 impulses/s) (Hensel and Kenshalo, 1969). Therefore, it can be concluded that thermoreceptor data reported in literature differ considerably.

In addition to the steady-state discharge rate, timedependent changes in skin temperature (i.e., direction and rate of temperature change) also influence the discharge rate. For instance, warm-sensitive neurons increase their discharge rate when heated, and even more when strongly heated, whereas during cooling the discharge rate of warm-sensitive neurons is decreased (Figure 2).

The neural pathway from local thermal reception to thermal sensation is described in literature as follows (Craig et al., 2000; Morrison, 2011). (i) The thermoreceptors bring the information to the spinal cord (i.e., from peripheral skin and deep body tissues) and to the trigeminal nucleus (i.e., from face skin). (ii) From the dorsal horn (top of spinal cord) and trigeminal nucleus, second-order neurons project to the thalamus. This is a different pathway than for thermoregulation, because for thermoregulation the secondary neurons connect to

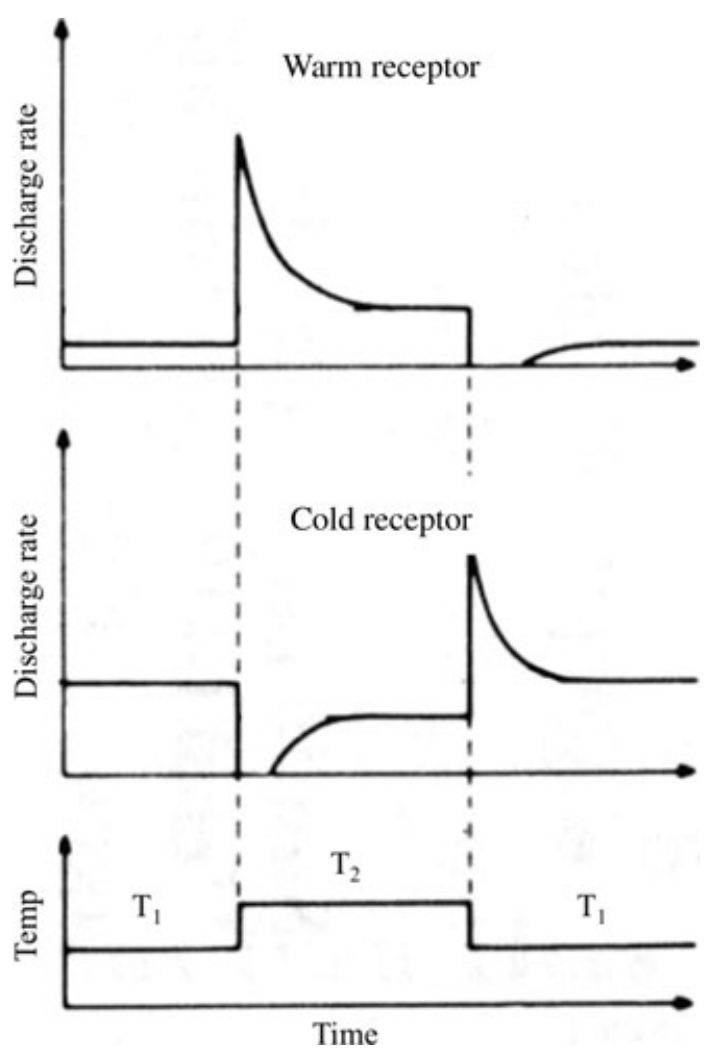

Fig. 2 Schematic view of dynamic neuron discharge rate of temperature sensitive neurons. With increasing temperature warm thermoreceptors show an initial overshoot in discharge rate and cold thermoreceptors show an initial undershoot. Vice versa for decreasing temperature. Modified from Hensel (1981)

the hypothalamus instead of the thalamus (Benzinger, 1969; Morrison, 2011). (iii) The thalamus projects to the insular cortex, which is presumed to be the brain area for perception and localization of thermal stimulus intensity (Craig et al., 2000).

\section{Methods}

The mathematical model developed in this study uses experimentally measured skin and core temperature as input variables. Temperature recordings were then transduced to their equivalent neuron discharge rate. Finally, the neuron discharge rates were correlated to the experimentally measured sensation votes.

\section{Experiments}

In this study, two data sets of independent experiments were used. The first data set was used for development of the model; the second data set was used for validation. In both studies, core temperature was measured with an ingested telemetric pill (Cortemp, HQ Inc., Palmetto, FL, USA). The skin temperatures were measured according to ISO 9886 (2004) by wireless iButtons (Thermochron iButton_DS1291H, Dallas Maxim) at the 14-points as proposed by ISO 9886 (2004) (Parsons, 
Table 2 Subject characteristics in experiments used for model development and for validation

\begin{tabular}{lll}
\hline & Model development $(N=12)$ & Validation $(N=8)$ \\
\hline Age (year) & $24.9 \pm 1.0$ & $23.6 \pm 1.2$ \\
Mass $(\mathrm{kg})$ & $76.1 \pm 3.3$ & $82.7 \pm 8.6$ \\
Height $(\mathrm{m})$ & $1.80 \pm 0.02$ & $1.83 \pm 0.11$ \\
Body fat $(\%)$ & $16.7 \pm 1.4$ & $14.5 \pm 3.3$ \\
BMl $\left(\mathrm{kg} / \mathrm{m}^{2}\right)$ & $23.4 \pm 0.9$ & $24.8 \pm 3.1$ \\
\hline
\end{tabular}

2003; Van Marken Lichtenbelt et al., 2006). Thermal sensation votes were asked on a continuous seven-point thermal sensation interval scale, where each point on the line could be marked (ASHRAE, 2005). As a result, the thermal sensation could be assessed within \pm 0.05 scale unit of accuracy. The AHRAE thermal sensation scale is represented in Table 1.

For the development dataset, male participants were lying and wearing shorts only $(0.04 \mathrm{Clo})$. Firstly, participants were exposed to baseline air temperature $\left(30^{\circ} \mathrm{C}, 0.5 \mathrm{~h}\right)$. Next, participants were exposed to mild cold followed by warm conditions $\left(20^{\circ} \mathrm{C}, 1 \mathrm{~h} ; 35^{\circ} \mathrm{C}\right.$, $1 \mathrm{~h})$. Finally, participants were exposed to baseline conditions again for $1 \mathrm{~h}$ (Kingma et al., 2011). For the validation data set, male participants were sedentary and dressed (1.0 clo, including desk chair). The participants were exposed to a transient condition; temperature range: $17-25^{\circ} \mathrm{C}$, duration: $8 \mathrm{~h}$, temperature drift: first $4 \mathrm{~h}:+2^{\circ} \mathrm{C} / \mathrm{h}$, last $4 \mathrm{~h}:-2^{\circ} \mathrm{C} / \mathrm{h}$ (Schellen et al., 2010). Thus, participants were exposed to considerably different conditions in both datasets. Subject characteristics are shown in Table 2.

\section{Modeling of thermal reception and neural pathways}

For the development phase of the thermosensation model, skin temperature and core temperature recordings were used. First, the discharge rates of skin cold $(C)$ and warm $(W)$ thermal receptors and core warm $\left(H_{\text {warm }}\right)$ receptors were calculated as described below.

\section{Calculation of neuron discharge rate}

As described in the introduction, different thermoreceptor data exist in literature. However, with respect to

Table 1 Seven-point ASHRAE thermal sensation scale (ASHRAE, 2004)

\begin{tabular}{ll}
\hline Thermal sensation & Corresponding term \\
\hline-3 & Cold \\
-2 & Cool \\
-1 & Slightly cool \\
0 & Neutral \\
+1 & Slightly warm \\
+2 & Warm \\
+3 & Hot \\
\hline
\end{tabular}

mathematical modeling of thermoreceptor data, only a study by Mekjavic and Morrison (1985) was found (Mekjavic and Morrison, 1985). They based their mathematical neuron discharge rate model on the thermoreceptor data presented by Zotterman (1953). Therefore, the simulated discharge rate of temperaturesensitive neurons at the periphery is modeled as a steady-state discharge rate and dynamic response to temperature changes and according to Mekjavic and Morrison (1985):

$$
\begin{aligned}
c_{t}= & (1 / \Delta t) \Sigma_{j}\left(S_{t-\Delta t}+\left(A_{0}(1-\exp (-j / K))\right.\right. \\
& \left.\left.+D A\left(\exp \left(-j / K_{e}\right)-\exp \left(-j / K_{i}\right)\right)\right)\right) .
\end{aligned}
$$

Here, $c_{t}$ is the discharge rate for cold-sensitive neurons at timepoint $t$ ( $w_{t}$ for warm-sensitive neurons), Summation over $j$ from $j=0$ to Delta $t-1, S_{t-\Delta t}$ is the steady-state neuron discharge rate at $t=t-\Delta t, A_{0}$ and $A$ are gain factors that depend on the difference of steady-state discharge rates between two moments of time $\left(A_{0}=S_{t-\Delta t}-S_{t}\right.$ and $\left.A=5.0 S_{t-\Delta t}\left|A_{0}\right|\right) . K=5.5$, $K_{\mathrm{i}}=3.3$, and $K_{\mathrm{e}}=5.5$ are static, inhibitory, and excitatory gain factors, respectively. $D$ is a sign operator indicating an excitatory or inhibitory response. When cold-sensitive neurons are heated, $D$ is negative, when the same neurons are cooled, $D$ is positive and vice versa for warm-sensitive neurons. The steady-state discharge rate of neurons is calculated as:

$$
S_{t}=\Sigma_{j} x_{j} T^{j}
$$

where $x_{j}$ is the $j$-th order coefficient as given in Table 3 and $T$ is the local temperature. The steady-state response of core temperature neurons is also calculated according to Mekjavic and Morrison (1985) by shifting measured core temperature by $-2^{\circ} \mathrm{C}$.

Local skin temperatures were used instead of mean skin temperature; using mean skin temperature would lead to significant errors in calculation of the average

Table 3 Coefficients to calculate the static neuron discharge rate of cold and warm sensitive neurons [values are modified from Mekjavic and Morrison (1985)

\begin{tabular}{lcc}
\hline Coefficient & Cold sensitive neuron & Warm sensitive neuron \\
\hline$x_{0}$ & $-0.19005313 \mathrm{e}-6$ & $0.1526647 \mathrm{e}-5$ \\
$x_{1}$ & $0.85318078 \mathrm{e}-5$ & $-0.5147704 \mathrm{e}-4$ \\
$x_{2}$ & $-0.16974919 \mathrm{e}-5$ & $0.7707699 \mathrm{e}-3$ \\
$x_{3}$ & $0.19724509 \mathrm{e}-4$ & $-0.67475955 \mathrm{e}-2$ \\
$x_{4}$ & $-0.14833377 \mathrm{e}-3$ & $0.38244284 \mathrm{e}-1$ \\
$x_{5}$ & $0.75486723 \mathrm{e}-1$ & $-0.14664175 \mathrm{e}-0$ \\
$x_{6}$ & $-0.26343323 \mathrm{e}-0$ & $0.38526706 \mathrm{e}-2$ \\
$x_{7}$ & $0.62289589 \mathrm{e}-2$ & $-0.68496075 \mathrm{e}-4$ \\
$x_{8}$ & $-0.95563808 \mathrm{e}-4$ & $0.78889647 \mathrm{e}-6$ \\
$x_{9}$ & $0.85949930 \mathrm{e}-6$ & $-0.53173142 \mathrm{e}-8$ \\
$x_{10}$ & $-0.34432887 \mathrm{e}-8$ & $0.15936041 \mathrm{e}-10$ \\
\hline
\end{tabular}


discharge rate of temperature-sensitive neurons, owing to the nonlinear characteristic of neuron discharge rate vs. temperature. For instance, the average discharge rate of two cold-sensitive neurons with temperature $\left(T_{1}=20^{\circ} \mathrm{C}\right.$ and $\left.T_{2}=30^{\circ} \mathrm{C}\right)$ is not equal to the discharge rate of a neuron with temperature $T_{\text {mean }}=25^{\circ} \mathrm{C}$ (see Figure 1). Local neuron discharge rates are integrated at the spinal cord. This is calculated by averaging neuron discharge rate over skin positions $\left(P_{\text {warm }}=\Sigma W / n\right.$ and $\left.P_{\text {cold }}=\Sigma C / n\right)$. Here, $P_{\text {warm }}$ and $P_{\text {cold }}$ ( $P$ stands for peripheral) are the averaged (i.e., integrated) peripheral warm and peripheral cold discharge rates and $n$ is the number of positions where skin temperature is experimentally measured. From the horn (i.e., top of spinal cord), second-order neurons project to the thalamus and from the thalamus further to the insular cortex. There the thermal information from the body core $\left(H_{\text {warm }}\right)$ and skin $\left(P_{\text {cold }}\right.$ and $\left.P_{\text {warm }}\right)$ is integrated. Some hypotheses on the neural pathways involved in thermal sensation exist (Chatonnet et al., 1966; de Dear, 2011). Therefore, we developed several models where the subject averaged thermal sensation vote was used as a dependent variable (see Table 4). Each model represents a different hypothesis, or assumption, of the neural pathway involved in thermal sensation. All variables are expressed in the discharge rate unit impulses per second'. Therefore, the model coefficient signs define excitation and inhibition within the neural pathway, a positive sign denotes excitation and a negative sign denotes inhibition. The first model is based on the assumption that only skin thermoreception contributes to thermal sensation (de Dear, 2011). The second model assumes that all three forms of thermoreception (i.e., skin cold thermoreception, skin warm thermoreception, and core warm thermoreception) project individually to the thermal sensation (Chatonnet et al., 1966). The third model assumes that core body thermoreception and skin warm thermoreception contribute to thermal sensation. Finally, the fourth model assumes that core body thermoreception and skin cold thermoreception contribute to thermal sensation.

The neuron discharge rates were correlated to the experimentally measured sensation votes by multiple regression analysis. All calculations were performed

Table 4 Thermosensation models that were tested on experimental data

\footnotetext{
$S=\beta_{0}+\beta_{1} P_{\text {cold }}+\beta_{2} P_{\text {warm }}$

$S=\beta_{0}+\beta_{1} H_{\text {warm }}+\beta_{2} P_{\text {cold }}+\beta_{3} P_{\text {warm }}$

$S=\beta_{0}+\beta_{1} H_{\text {warm }}+\beta_{2} P_{\text {warm }}$

$S=\beta_{0}+\beta_{1} H_{\text {warm }}+\beta_{2} P_{\text {cold }}$

(1)

(2)

(3)

(4)

$S$ is the thermal sensation vote as defined on the seven-point ASHRAE scale for thermal sensation. $H_{\text {warm }}$ (impulse/s) is the neuron discharge rate corresponding to measured core temperature. $P_{\text {cold }}$ (impulse/s) is the averaged neuron discharge rate of skin cold sensitive thermoreceptors. $P_{\text {warm }}$ (impulse/s) is the averaged neuron discharge rate of skin warm sensitive thermoreceptors.
}

using Matlab 2010a for Mac. Only one model was selected for validation against the independent data set. Model selection for validation was based on the following criteria: (i) all $\beta$-coefficients significantly differed from zero (ii) highest explained variance (i.e., highest $r^{2}$-value).

\section{Validation}

The thermo sensation model was validated by calculation of the root mean squared residual (RMSR) between model prediction and measured sensation votes of the validation data set. The model prediction quality was considered acceptable when RMSR $<1$, thus the model prediction should be within 1-scale points of the measured sensation vote. This value was based on a power calculation to have $95 \%$ chance to detect a significant error in model prediction using $N=8$ subjects for validation. Given the variation in sensation votes as estimated from the development dataset, a statistical detection power of $95 \%$ is feasible when the average prediction error $\geq 1$-scale unit. The power calculation for the 'one-sample test' is as follows:

$$
Z \gamma=\left(n \delta^{2} / \sigma^{2}\right)^{0.5}-Z_{0.5} \alpha
$$

Here, $Z \gamma$ is the value of the standard normal distribution corresponding to the type II error rate (power $=1-\gamma=0.95), n$ is the sample size $(N=8), \delta$ is the prediction error, $\sigma$ is the standard deviation as estimated from the development dataset, and $Z_{0.5} \alpha$ is the value of the standard normal distribution corresponding to the type I error rate $(\alpha=0.05)$.

Model prediction was performed by repetition of the thermoreceptor discharge rate calculation procedure as described in the model development phase. However, now, skin and core temperature data from the validation data set were used.

\section{Results}

Model development phase

Regression analysis revealed that all models, each with different assumptions on the neural pathways, significantly explained the thermal sensation vote (see Table 5). However, only in model 3 and model 4 did all $\beta$-coefficients differ significantly from zero. In models 2 through 4 , the core warm thermoreception pathway had a significant negative contribution to the thermal sensation. Hence, during the mild thermal challenge, a decrease in core temperature related to a warm thermal sensation. In model 3, the skin warm thermoreception pathway had a significant positive contribution to the thermal sensation. Thus, warm or heated skin related to a warm thermal sensation. Vice 


\section{Kingma et al.}

Table 5 Regression coefficients $\pm 95 \% \mathrm{Cl}\left(\beta\right.$ 's) with the corresponding variable, explained variance $\left(r^{2}\right)$, and $P$-value of sensation models during development phase

\begin{tabular}{|c|c|c|c|c|c|c|}
\hline Model & $\beta_{0}$ & $\beta_{1}$ & $\beta_{2}$ & $\beta_{3}$ & $r^{2}$ & $P$-value \\
\hline 1 & $-0.12 \pm 55.1$ & $-0.6 \pm 4.3\left(P_{\text {cold }}\right)$ & $1.9 \pm 9.6\left(P_{\text {warm }}\right)$ & & 0.81 & $<1.8 \times 10^{-6}$ \\
\hline 2 & $36.4 \pm 49.6$ & $-14.8 \pm 9.6\left(H_{\text {warm }}\right)^{*}$ & $0.7 \pm 3.5\left(P_{\text {cold }}\right)$ & $3.9 \pm 7.7\left(P_{\text {warm }}\right)$ & 0.89 & $<2.1 \times 10^{-7}$ \\
\hline 3 & $44.0 \pm 32.8^{*}$ & $-14.3 \pm 9.0\left(H_{\text {warm }}\right)^{*}$ & $2.3 \pm 0.9\left(P_{\text {warm }}\right)^{*}$ & & 0.89 & $<2.5 \times 10^{-8}$ \\
\hline 4 & $56.1 \pm 30.7^{*}$ & $-13.9 \pm 9.4\left(H_{\text {warm }}\right)^{*}$ & $-1.0 \pm 0.4\left(P_{\text {cold }}\right)^{*}$ & & 0.87 & $<8.2 \times 10^{-8}$ \\
\hline
\end{tabular}

${ }^{*} P<0.05$.
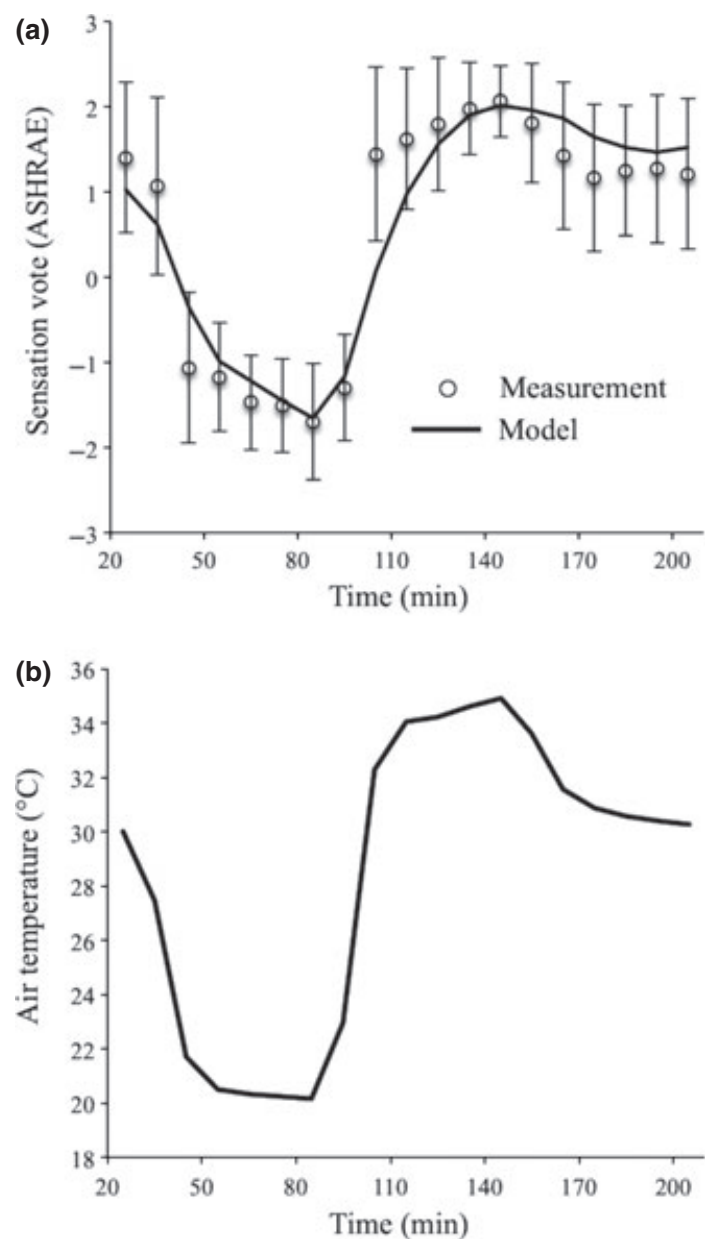

Fig. 3 (a) Averaged sensation votes and model fit (Model 3) of the development data set. Error bars represent the standard deviation. (b) Thermal condition to which participants were exposed

versa, in model 4, the skin cold thermoreception pathway had a significant negative contribution to the thermal sensation, such that cold or cooled skin related to a cold thermal sensation. The measured sensation votes and the prediction of model 3 on the development data set are shown in Figure 3.

\section{Model validation phase}

Model 3 was selected for the validation phase as it best explained the variation $\left(r^{2}=0.89\right)$. The sensation
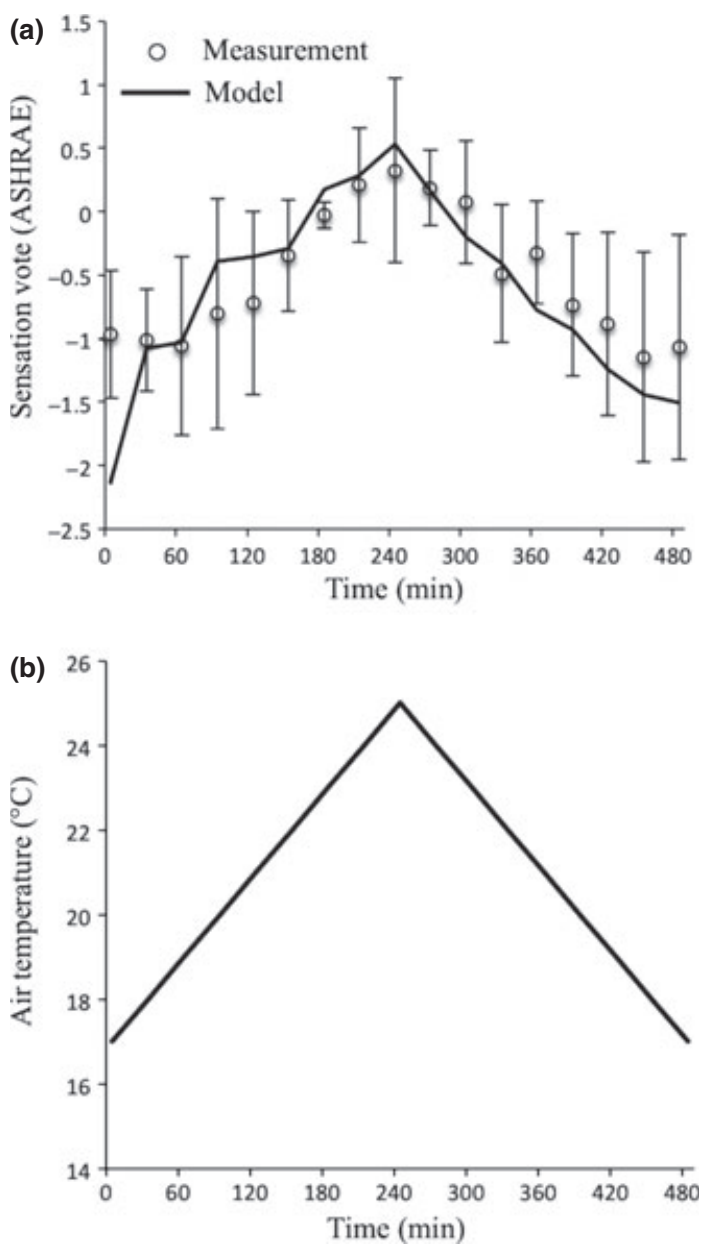

Fig. 4 (a) Averaged sensation votes and model prediction (Model 3) on the validation data set. Error bars represent the standard deviation. (b) Thermal condition to which participants were exposed

votes of the validation set and the model prediction are shown in Figure 4. The root mean square error (RMSR) of the thermal sensation prediction on the validation set was 0.38 , which means that on average there was a 0.38 prediction error in thermal sensation. The maximum error observed was 1.16 scale points at the beginning of the experiment. The minimum error observed was 0.02 scale points at $t=100 \mathrm{~min}$. In general, the model predictions were within the standard deviation of the measurements. 


\section{Discussion}

In this study, a mathematical model of thermal sensation based on neurophysiology was validated on an independent dataset. The results indicate that the simulation of the neural pathways was able to capture characteristics of thermal sensation. Such a model of human thermal sensation can be of great value in designing of high-performance buildings.

A comfortable environment could be described as an environment where the average rating of a group of persons is between -1 and +1 on the ASHRAE thermal sensation scale (Fanger, 1970; Parsons, 2003). The model developed in this study was able to predict thermal sensation within 0.5 -scale unit accuracy for both datasets (development and validation). Foda et al. (2011) found for four different thermal sensation models a discrepancy between predicted and measured overall thermal sensation within \pm 1.0 scale unit. Thus, the model presented in this paper provides a greater accuracy and therefore more detailed information can be obtained regarding the overall thermal sensation. In practice, this could be beneficial because small deviations from a neutral thermal sensation (i.e., an overshoot or undershoot in thermal sensation) could provide a more comfortable thermal environment (Humphreys and Hancock, 2007; Van Hoof, 2008).

In current building practice, the PMV model of (Fanger, 1970) is used to predict the future thermal sensation of occupants. However, as mentioned in the introduction this model has limitations regarding the prediction of thermal sensation (e.g., for different subpopulations). Van Hoof et al. (2010) concluded in an extensive literature review that multi-segmental models of human physiology have a large potential to predict high-resolution thermal sensation of occupants in both the design phase of a building and laboratory conditions (Van Hoof et al., 2010). Especially, a large potential exists for complex environments regarding non-uniform and transient conditions which, in the end, could turn out to be the most comfortable environments (de Dear, 2011). However, van Hoof et al. also concluded that it is a great challenge to link the outcomes of a thermophysiological model to thermal sensation.

Until now, few studies have been available where physiological responses are related to thermal sensation. All current models require a body temperature setpoint to simulate thermal sensation. Fiala (1998) developed the dynamic thermal sensation (DTS) model to predict the dynamic thermal sensation based on core temperature, mean skin temperature, and rate of change in mean skin temperature (Fiala, 1998). Another study conducted by Zhang et al. (2010a,b,c) related physiological responses to local thermal sensation based on differences between local skin temperature and the setpoint of skin temperature for a specific body part, rate of change in local skin temperature, and rate of change in core temperature (Zhang et al., 2010a,b,c). Although these models show promising results, one could argue whether setpoints are a good representation of the physiology behind thermoregulation or thermal sensation (Cabanac, 2006; Romanovsky, 2007).

In this study, a thermal sensation model was developed based on the neurophysiology of thermal reception and neural integration. Several hypotheses of the neural pathways that predict thermal sensation were tested (see Table 5). Interestingly, the best model only required thermal information from warm-sensitive receptors of skin and core. The reason for this becomes clear after analysis of simulated core and skin thermoreception over time. Figure 5 shows the simulated neuron discharge rate for core warm receptors $\left(H_{\text {warm }}\right)$ and integrated skin cold $\left(P_{\text {cold }}\right)$ and warm ( $\left.P_{\text {warm }}\right)$ receptors. The signals of $P_{\text {cold }}$ and $P_{\text {warm }}$ are almost mirrored images of each other; therefore, both signals contain the same information. It is possible that in more extreme situations (colder, hotter, or larger temperature changes), information of both cold and warm skin receptors is necessary to correctly predict thermal sensation. For instance, when skin temperature decreases below $26^{\circ} \mathrm{C}$, temperature information is dominated by the discharge rate of skin cold-sensitive thermoreceptors (Figure 1): the discharge rate of warm-sensitive thermoreceptors decreases to zero. Likewise, above $35^{\circ} \mathrm{C}$, virtually no skin cold thermoreceptor input is generated, and all information is coded by skin warm thermoreceptors (Figure 1). In more neutral environments, however, skin warm and cold thermoreceptors seem to reveal the same. To the best of our knowledge, only one other study correlated thermal reception to thermal sensation (de Dear et al., 1993). de Dear et al. showed that the change in thermal sensation correlated to the discharge rate of both cold and warm skin thermoreceptors during a sudden ambient temperature transition. The authors did not report correlations to absolute sensation votes. The results presented in this paper suggest that apart from skin thermal reception, absolute thermal sensation is also dependent on warm core thermoreceptors. It could be that skin thermoreceptors correlate well to changes in thermal sensation, yet the core thermoreceptors are important for an absolute 'basal' level of thermal sensation. We will again illustrate this with Figure 5. This figure shows that there is a delayed response of the core thermoreceptors relative to the skin thermoreceptors $(t=30-90 \mathrm{~min})$. The warm core thermoreceptors decrease their discharge rate (Figure 5, Top), while skin thermoreception already returned to near baseline values (Figure 5, Bottom). Note that the delay of core thermoreception might differ depending of the exact site and method of core temperature measurement (Benzinger, 1969; Teunissen et al., 2011). Owing to the 


\section{Kingma et al.}

(a)
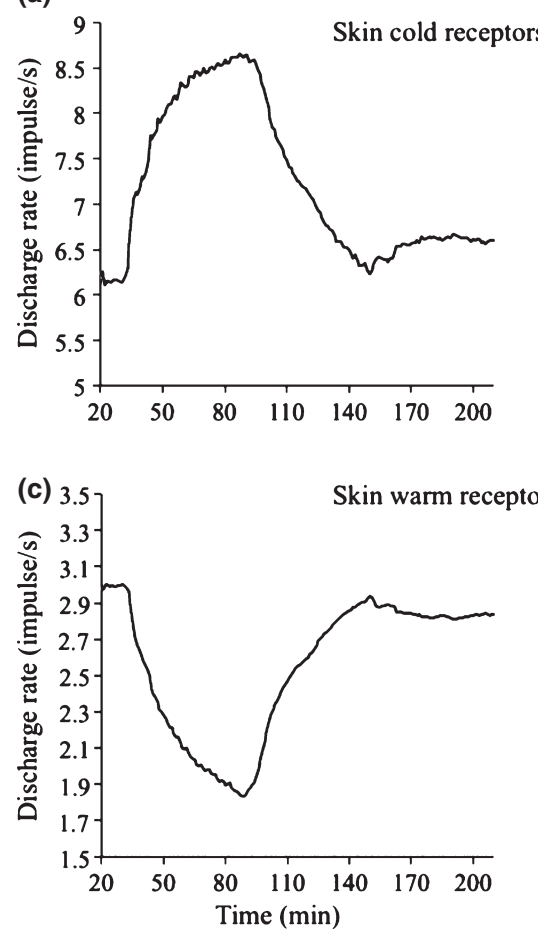

(b)
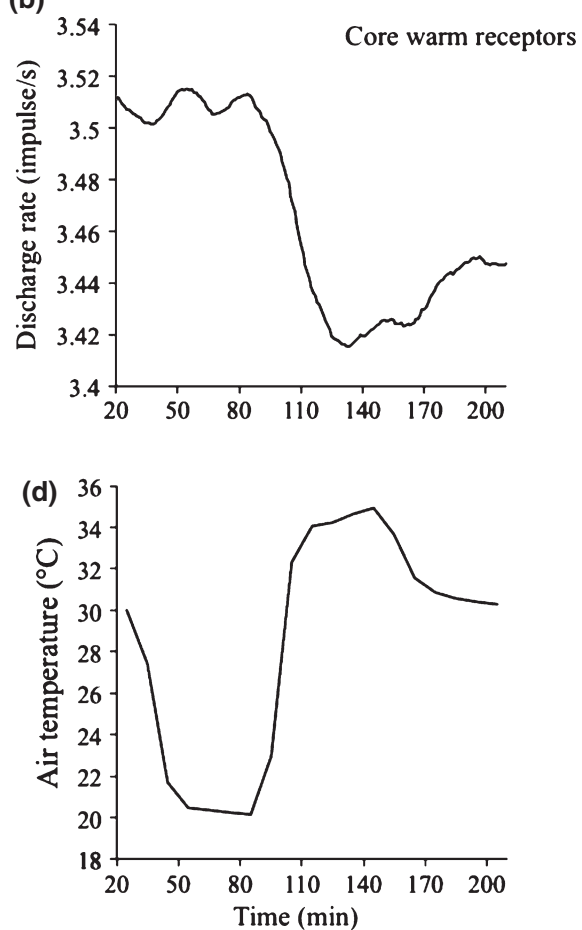

Fig. 5 Simulated thermoreceptor discharge rates of: (a) skin cold thermoreceptors $\left(P_{\text {cold }}\right)$; (b) core warm thermoreceptors $\left(H_{\text {warm }}\right)$; and (c) skin warm thermoreceptors $\left(P_{\text {warm }}\right)$. (d) The thermal condition participants were exposed to

slow response, abdominal core thermoreception cannot be associated with thermal sensation during sudden ambient temperature transitions. However, during rewarming, the afterdrop in core temperature is clearly visible in the core warm thermoreception. An afterdrop in core temperature is caused by the return of cooled blood from the peripheral tissues (Severens et al., 2007). Although the range of the discharge rate change for core warm thermoreceptors is not as large as for skin warm thermoreceptors ( $H_{\text {warm: }}$ 3.4-3.5 pulse $/ \mathrm{s}$ and $\left.P_{\text {warm }}: 1.9-3.1 \mathrm{pulse} / \mathrm{s}\right)$, the associated weight $(\beta)$ is considerably larger for core thermoreception than for skin thermoreception $\left(\beta_{H_{\text {warm }}}=-14.3\right.$ and $\beta_{P_{\text {warm }}}=2.3$ ), which evens out the difference in discharge rate. Hence, core thermoreception has a large long-lasting influence on thermal sensation and skin thermoreception has a fast changing influence on thermal sensation. The negative sign of the core warm thermoreception pathway model coefficient may seem counter-intuitive at first, because it suggests that a decrease in core temperature relates to a warm thermal sensation. However, during the mild thermal challenge, core temperature remained stable during mild cold, yet during rewarming, core temperature dropped on average by $0.3^{\circ} \mathrm{C}$ (Kingma et al., 2011). A paradoxical decrease in core temperature during rewarming or an increase in core temperature during mild cold has been described in physiological literature (Benzinger, 1969;
Sessler, 2000). The inverse relation between core temperature change and thermal sensation during a mild thermal challenge might be part of thermal alliesthesia, as during stable conditions a high core temperature is associated with to a warm thermal sensation and thermal discomfort (Mayer, 1993). Another issue for thermal alliesthesia relates to the dominance of thermoreception to thermal sensation. When the thermal environment continuously changes, there is a large contribution of thermoreception to the overall thermal sensation. This can be explained by the importance of detecting changes in the thermal environment to maintain thermal homeostasis. However, when the ambient environment is more stable, the relative influence of non-thermal factors may increase. Therefore, thermoreception and thermal sensation may have a stronger coupling during thermal transients relative to stable thermal conditions. Overall, this suggests that the currently developed model may be suitable for predicting thermal sensation during transient thermal conditions, yet less so during stable thermal conditions.

The model presented in this study relies on simulated neuron discharge rate. In literature, different experimentally measured thermoreceptor data exist. For instance, a study by Hensel and Kenshalo (1969) showed a near 10-fold increase in the maximum steady-state discharge rate of warm-sensitive neurons 
in comparison with the data presented by Zotterman (1953) (36 impulses/s vs. 4 impulses/s, respectively). Especially during transient conditions, such differences could have a large impact on model performance, which is mainly because the magnitude of the dynamic response scales with the difference between two steady-state discharge rates. For instance, when a warm-sensitive neuron is heated using the data presented by Hensel and Kenshalo (1969), a higher steady-state discharge rate would also result in a larger dynamic response. Vice versa, when a warmsensitive neuron is cooled, its discharge rate is also suppressed more. Theoretically, cooling could even nullify the discharge rate of warm-sensitive neurons, leaving only cold-sensitive neurons to obtain information on the thermal status of the body. Therefore, future studies should elucidate how using different thermoreceptor data might alter the results of this study.

In summary, the neurophysiological approach for developing a mathematical thermal sensation model as presented in this paper offers a method to predict the thermal sensation under complex non-uniform and transient mild thermal environments. Furthermore, this approach can be extended to a thermal sensation prediction on a local body part level; however, more research is needed for this. Therefore, future work should focus on:

- relative importance of specific skin areas to whole body thermal perception,

- relative importance of core temperature measurement site to thermal perception,

- thermoreception in more extreme environments (e.g., colder, warmer, and larger temperature changes),

- steady-state thermoreception characteristics,

- inclusion of other subpopulations such as, females, older people, or people with obesity,

- application of local thermoreception to local comfort.

\section{Conclusion}

In this study, a new model for predicting thermal sensation is developed. This model is based on the neurophysiology of thermal reception. The model is validated on an independent dataset. The only dependent parameters for thermal sensation in the model are core body warm thermoreception and skin warm thermoreception. The model was capable to significantly predict thermal sensation within 0.5 -scale unit accuracy for both the development dataset and the validation dataset. In current building practice, an accuracy of \pm 1.0 is considered as acceptable. Though, rather small deviations from optimum (neutral), <1.0scale unit could provide a more comfortable thermal environment and occupants would therefore be more satisfied with their environment. The presented method can be highly beneficial for predicting thermal sensation under complex environments with respect to nonuniform and transient environments, especially in combination with thermophysiological models to link physiological responses to thermal sensation. Therefore, the neurophysiological model of thermal sensation can be of great value in the design of highperformance buildings.

\section{Acknowledgements}

This research was funded by Agentschap NL (formerly Senternovem), an agency of the Dutch Ministry of Economic Affairs. Their financial contribution is gratefully acknowledged. The authors express their gratitude to the participants in the experiments. Appreciation is also expressed to the staff of the laboratory of the department Human Biology of the Maastricht University and the staff of the laboratory of the Unit Building Physics and Systems (BPS) of Eindhoven University of Technology for their valuable assistance.

\section{References}

Arens, E., Zhang, H. and Huizenga, C. (2006) Partial- and whole-body thermal sensation and comfort - Part II: nonuniform environmental conditions, J. Therm. Biol., 31, 60-66.

ASHRAE (2004) Standard 55: Thermal Environmental Conditions for Human Occupancy, ASHRAE.

Benzinger, T.H. (1969) Heat regulation: homeostasis of central temperature in man, Physiol. Rev., 49, 671-759.

Boerstra, A., Opt Veld, P. and Eijdems, H. (2000) The Health, Safety and Comfort Advantages of Low Temperature Heating Systems - A Literature Review, Healthy Buildings, Espoo, Finland.
Boulant, J.A. (2006) Neuronal basis of Hammel's model for set-point thermoregulation, J. Appl. Physiol., 100, $1347-$ 1354.

Cabanac, M. (2006) Adjustable set point: to honor Harold T. Hammel, J. Appl. Physiol., 100, 1338-1346.

Chatonnet, J., Thiers, H., Cabanac, M. and Pasquier, J. (1966) On the origin of conscious impression of thermal comfort, Lyon Med., 216, 13871392.

Craig, A.D., Chen, K., Bandy, D. and Reiman, E.M. (2000) Thermosensory activation of insular cortex, Nat. Neurosci., 3, 184-190. de Dear, R. (2011) Revisiting an old hypothesis of human thermal perception: alliesthesia, Building Res. Inf., 39, 108117.

de Dear, R. and Brager, G.S. (2001) The adaptive model of thermal comfort and energy conservation in the built environment, Int. J. Biometeorol., 45, 100-108.

de Dear, R., Ring, J.W. and Fanger, P.O. (1993) Thermal sensations resulting from sudden ambient temperature changes, Indoor Air, 3, 181-192.

Dodt, E. and Zotterman, Y. (1952) Mode of action of warm receptors, Acta Physiol. Scand., 26, 345-357. 


\section{Kingma et al.}

ECBCS (2007) Available online at http:// www.ecbcs.org, accessed on February, 2011.

Fanger, P.O. (1970) Thermal comfort, PhD Thesis, Copenhagen, Danish Technical University.

Fiala, D. (1998) Dynamic Simulation of Human Heat Transfer and Thermal Comfort. $\mathrm{Ph}$. D. thesis, Stuttgart, De Montfort University, Institute of Energy and Sustainable Development.

Foda, E., Almesri, I., Awbi, H.B. and Siren, K. (2011) Models of human thermoregulation and the prediction of local and overall thermal sensations, Build. Environ., 46, 2023-2032.

Hensel, H. (1981) Thermoreception and Temperature Regulation, London, Academic Press Inc Ltd.

Hensel, H. and Kenshalo, D.R. (1969) Warm receptors in the nasal region of cats, J. Physiol., 204, 99-112.

Humphreys, M.A. and Hancock, M. (2007) Do people like to feel 'neutral'? Exploring the variation of the desired sensation on the ASHRAE scale, Energy Build., 39, 867-874.

Juusela, M.A. (2003) Guidebook to IEA ECBCS Annex 37. Heating and Cooling with Focus on Increased Energy Efficiency and Improved Comfort, Espoo, VTT Building and Transport.

Johnson, F., Mavroggiani, A., Ucci, M., Vidal-Puig, A. and Wardle, J. (2011) Could increased time spent in a thermal comfort zone contribute to population increases in obesity?, Obes. Rev., 12, 543551.

Kingma, B.R., Frijns, A.J., Saris, W.H., Van Steenhoven, A.A. and Van Marken Lichtenbelt, W.D. (2011) Increased systolic blood pressure after mild cold and rewarming: relation to cold-induced thermogenesis and age, Acta physiol., 203, 419-427.
Mayer, E. (1993) Objective criteria for thermal comfort, Build. Environ., 28, 399-403.

Mekjavic, I.B. and Morrison, J.B. (1985) A model of shivering thermogenesis based on the neurophysiology of thermoreception, IEEE Trans. Biomed. Eng., 32, 407417.

Morrison, S.F. (2011) 2010 Carl Ludwig distinguished lectureship of the APS neural control \& autonomic regulation section: central neural pathways for thermoregulatory cold defense, J. Appl. Physiol., 5, 1137-1149.

Nakano, J., Tanabe, S. and Kimura, K. (2002) Differences in perception of indoor environment between Japanese and nonJapanese workers, Energy Build., 34, 615621.

Parsons, K. (2002) The effects of gender, acclimation state, the opportunity to adjust clothing and physical disability on requirements for thermal comfort, Energy Build., 34, 593-599.

Parsons, K. (2003) Human Thermal Environments, London, Taylor \& Francis.

Romanovsky, A.A. (2007) Thermoregulation: some concepts have changed. Functional architecture of the thermoregulatory system, Am. J. Physiol. Regul. Integr. Comp. Physiol., 292, R37R46.

Schellen, L., Van Marken Lichtenbelt, W.D., Loomans, M.G., Toftum, J. and De Wit, M.H. (2010) Differences between young adults and elderly in thermal comfort, productivity, and thermal physiology in response to a moderate temperature drift and a steady-state condition, Indoor Air, 20, 273-283.

Sessler, D.I. (2000) Perioperative heat balance, Anesthesiology, 92, 578-596.

Severens, N.M., Van Marken Lichtenbelt, W.D., Van Leeuwen, G.M., Frijns, A.J., Van Steenhoven, A.A., De Mol, B.A., Van Wezel, H.B. and Veldman, D.J.
(2007) Effect of forced-air heaters on perfusion and temperature distribution during and after open-heart surgery, Eur. J. Cardiothorac. Surg., 32, 888-895.

Teunissen, L.P., Klewer, J., De Haan, A., De Koning, J.J. and Daanen, H.A. (2011) Non-invasive continuous core temperature measurement by zero heat flux, Physiol. Meas., 32, 559-570.

Van Hoof, J. (2008) Forty years of Fanger's model of thermal comfort: comfort for all?, Indoor Air, 18, 182-201.

Van Hoof, J., Mazej, M. and Hensen, J.L. (2010) Thermal comfort: research and practice, Front. Biosci., 15, 765-788.

Van Marken Lichtenbelt, W.D., Daanen, H.A., Wouters, L., Fronczek, R., Raymann, R.J., Severens, N.M. and Van Someren, E.J. (2006) Evaluation of wireless determination of skin temperature using iButtons, Physiol. Behav., 88, 489497.

Zhang, H., Arens, E., Huizenga, C. and Han, T. (2010a) Thermal sensation and comfort models for non-uniform and transient environments, part II: local comfort of individual body parts, Build. Environ., 45, 389-398.

Zhang, H., Arens, E., Huizenga, C. and Han, T. (2010b) Thermal sensation and comfort models for non-uniform and transient environments, part III: Whole-body sensation and comfort, Build. Environ., 45, 399-410.

Zhang, H., Arens, E., Huizenga, C. and Han, T. (2010c) Thermal sensation and comfort models for non-uniform and transient environments: part I: local sensation of individual body parts, Build. Environ., 45, 380-388.

Zotterman, Y. (1953) Special senses: thermal receptors, Annu. Rev. Physiol., 15, 357372. 